\title{
Does the Cognitive Top-Down Systems Biology Approach, Embodied in Virtual Scanning, Provide Us with a Theoretical Framework to Explain the Function of Most Complementary and Alternative and Most Orthodox Biomedical Techniques?
}

\author{
Graham Wilfred Ewing \\ Additional information is available at the end of the chapter
}

http://dx.doi.org/10.5772/50441

\section{Introduction}

Perhaps the greatest challenge faced by advocates of complementary or alternative therapies is the lack of a theoretical concept to explain why such techniques can have a therapeutic or diagnostic effect. If there is not a theoretical concept or explanation it follows that the use of such techniques often cannot be adapted in a methodical or scientific manner. If there is not an objective and/or accurate means of identifying the emergence of the health problem then there cannot be an objective means of treating the problem. It may also mean that the outcomes of such techniques are experiential and unreliable, different practitioners get variable results, different techniques or combination of techniques could have adverse sideeffects, etc. The lack of a robust theoretical concept to explain the body's dysfunction and the role of drugs, which are only circa $50 \%$ effective in $90 \%$ of the population ${ }^{1}$, is also a fundamental limitation of orthodox biomedicine. No-one has yet been able to explain how the body regulates its function.

Many clinical studies have illustrated that some CAM techniques are able to provide a diagnostic or therapeutic effect. Moreover many drugs and medical techniques have their origins in what we know as CAM. The therapeutic application of plant extracts, the development of penicillin, the use of X-rays, etc; are all derived from naturally occurring phenomenae. 
Any explanation for CAM techniques must fit into established concepts and theories which prevail in science. Anything which cannot be thus explained should be discarded in favour of more robust explanations. If a technique has a proven diagnostic or therapeutic effect it will be adapted for use by the medical profession although perhaps in recent years it has become more difficult to introduce new technologies into the major regulated markets i.e. due to the increased cost of developing and validating such techniques, lack of basic research in non-pharma techniques, and perhaps also opposition from those with established market share and hence of vested interests who seek to maintain the status quo. Nevertheless if the technology has a commercial significance entrepreneurs will evaluate the opportunity, invest and develop the opportunity e.g. light-based techniques are used in different forms of optometry.

Orthodox biomedicine has selectively assimilated CAM research into its realm e.g. the pharmaceutical company GSK has been researching polyclonal antibodies which are more typically associated with the antibody response in homeopathy, yet despite the proliferation/dominance of pharmacological research there is not an accepted understanding of the processes which lead to morbidity and mortality. There is no accepted understanding of how the body regulates its function ${ }^{2}$. Moreover, the requirement for medical care has increased by a factor of ten or more in the last 30 years. No-one has yet been able to offer a significant explanation for this explosion of morbidity. Despite the emphasis upon vaccines and drugs the occurrence of cognitive and physiological dysfunction in society continues to increase. Morbidity and mortality are associated with genetic and non-genetic changes. This leads us to consider the various factors (i) which lead to genetic change and (ii) which suppress the processes which the body requires to maintain its regulated function and which we recognise as our health and wellbeing i.e. the effect which viruses and hence of vaccines, bacterial infections, psychological or environmental stresses, genetically modified foods, and drugs have upon the body's function.

In general, drugs are designed to treat the symptoms of disease. As most disease is caused by the aforementioned factors it becomes evident that drugs do not and cannot treat the cause of disease but instead act upon the biological processes of dysfunction which arise from the dysregulation or destabilisation of the body's function. Drugs modulate, suppress or alter the production of metabolites from pathological processes and/or otherwise adapt the use of pharmacological entities to modify the body's function and reduce the symptoms of disease and associated causes of discomfort and morbidity. It is perceived that such effects may allow the natural process of regulation or homeostasis to be re-established. This overlooks that the brain is continually seeking, assessing and computing the means to better maintain or reestablish the body's physiological stability i.e. it will in many cases compensate for the effect which drugs have on the body's function. For example (i) psychological traumas influence heart function e.g. bereavement, divorce ${ }^{3}$, social isolation ${ }^{4}$, illnesses. In such cases drugs treat the symptoms of dysfunction caused by the trauma. (ii) Diabetes may be the first step in a cascade of pathologies leading to heart dysfunction, Alzheimer's disease, circulatory problems, etc. It is ultimately caused by the cognitive dysfunction and altered behaviour ${ }^{5}$ which governs calorific intake and the expenditure of energy. 
The idea that autonomic regulation takes the body back to a base or homeostatic state lacks validity. Every change to genotype and phenotype makes changes which are to some degree reversible or irreversible. Some genetic changes can be reversed, some relatively quickly, others more slowly over a longer period, and others may be irreversible e.g. changes to our DNA due to viral or vaccinal RNA, may be relatively short-lasting (months), or may last for the duration of our lifetime.

The historical evolutionary pathways of medicine have resulted in what we know as physiology and psychology i.e. the function of the body and the brain are studied separately. This historical legacy continues to influence the prevailing psychological/physiological paradigm and regards the brain's function to be almost completely separate from the body's function. In recent years there has been greater research in the biological processes taking place in the brain however this neuroscientific approach often overlooks the significance of visceral pathologies upon brain development, brain plasticity and hence upon neural function. In principle, this means that psychology is the mirror of physiology i.e. that what we see/experience from our external environment influences our internal environment and what we experience in our internal environment influences our cognition and behaviour i.e. the development of pathologies influences our behaviour (mood, emotional response, the way in which we behave, etc). In other words one person's output or behaviour (or that of external influences) can influence another person's sensory input and their expectations. This can be illustrated if we consider how the medical profession benefits from the power of association i.e. when a patient's ailment has reached the stage that they decide to consult their doctor (i) they make an appointment to see the doctor who (they perceive and better than anyone else) can improve their health; (ii) they travel to their local health clinic confident that this is the place where better health is prescribed; (iii) they meet the doctor who receives them in a positive yet sympathetic manner, who examines them and advises how their ailment can be cured; (iv) they are prescribed a pill or potion which the doctor assures them will alleviate their symptoms; (v) they are prescribed time away from the stresses of life. Irrespective of the healing power of the pharmaceutical product this is a hugely powerful psychological therapy or placebo effect.

By contrast the psychological environment in a hospital is a more complex and potentially more brutal environment. The patient attends the hospital in varying degrees of trepidation. The experience is largely negative i.e. they are in varying degrees of ill-health; feel vulnerable, lonely and perhaps scared; do not know anyone, and hence mistrust those involved in their treatment. The wards in which they reside during their hospital treatment often have abnormal levels of natural lighting or ventilation. The beds are often standard issue hospital beds which may leave them in some degree of discomfort. They will be advised of both positive outcomes and the risk of increased morbidity and the potential of mortality although they can expect to receive reassurance from staff. They will see others who have been treated leave the hospital in better health but also can expect to see the problems faced by other patients. It is a stressful environment lowering the level of the immune response which is not conducive to the healing process - hence the current 
emphasis upon getting patients to recuperate in their home environment at the earliest opportunity.

\section{The sensory interface}

We experience our external and internal environments through the sensory ${ }^{6}$ and visceral interfaces i.e.

i. Sensory input: light/sight, odour/smell, sound/hearing, taste, touch and voice.

The sensory perception i.e. of vision, hearing, smell, taste, touch and the vocal spectrum; is influenced by the extent of prevailing pathologies.

ii. Frequency

- Flashing lights can cause photosensitive epilepsy and migraine but can be also adapted to treat photosensitive migraine and dyslexia. They are indications of systemic function and dysfunction.

- $\quad$ The EEG frequency(s) are indicators of the physiological significance of an event e.g.

\begin{tabular}{|l|l|}
\hline \multicolumn{1}{|c|}{ Frequency Range } & \multicolumn{1}{c|}{ Effect } \\
\hline Gamma (30-60hz): & $\begin{array}{l}\text { taking a picture of our environment; experiencing a smell, } \\
\text { hearing a sound }\end{array}$ \\
\hline Beta (15-30hz): & coordinated sensory/physical activity \\
\hline Alpha (8-15hz): & $\begin{array}{l}\text { conscious thought; linking activity to physiological activities } \\
\text { or objectives such as hunger, thirst, warmth, sleep, } \\
\text { procreation; recognising danger. }\end{array}$ \\
\hline Theta (4-8hz): & $\begin{array}{l}\text { pain is an indicator of an inflammatory response, a precursor } \\
\text { of damage; the link between conscious thought and systemic } \\
\text { function/dysfunction. }\end{array}$ \\
\hline Delta (1-4hz): & $\begin{array}{l}\text { systemic function and regulation; damage; processes of } \\
\text { repair; critical illness/coma and sleep. }\end{array}$ \\
\hline
\end{tabular}

Table 1.

Gamma, Beta and Alpha frequencies function during the wakened hours and hence are associated with sensory perception and processing whilst Theta and Delta frequencies are evident throughout the 24 hour cycle and hence are associated with the body's physiology.

Changes to cell morphology are associated with the EEG or resonant frequencies e.g. theta frequencies are associated with pain management, altered cell morphology, the subconscious thought processes and fixation of memories whilst delta frequencies are linked to physical damage (e.g. in the comatose state) and the processes of repair (e.g. which require sleep to facilitate or enhance the production of essential hormones). They are the evidence for the body's multi-level function. 
- Accordingly knowledge of the resonant or frequency-related properties of organs and organ systems may be adapted with therapeutic effect e.g. to stimulate healing processes, to re-establish homeostasis, to improve sensory perception and coordination, to improve the fixation of memories, etc.

This is an area of research in which eminent Russian researchers have excelled 7,8 for many years.

iii. Visceral input: breathing/air, temperature/warmth, acidity/pH, moisture/dry, food/diet, and drink.

These environmental influences are our phenotype: each altering the rate at which physiological reactions and extractions proceed. It is through these mechanisms that we interact with our environment and deal with adverse influences.

\section{Gamma radiation X-rays Micro-wave radiation Ultrasound Gravity}

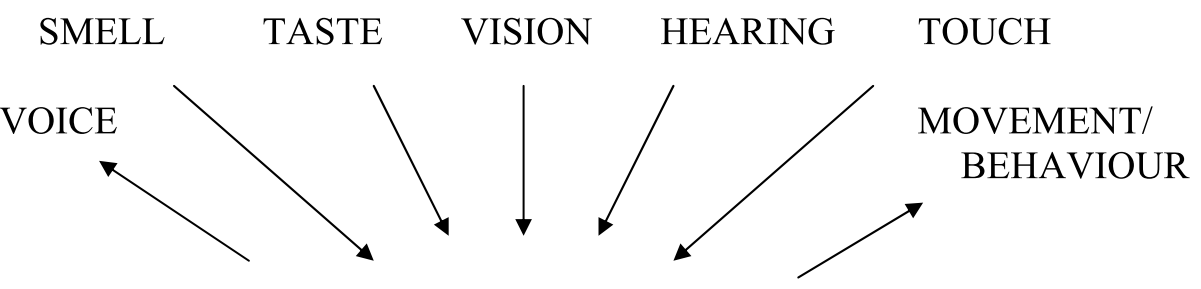

NEURAL MATRIX

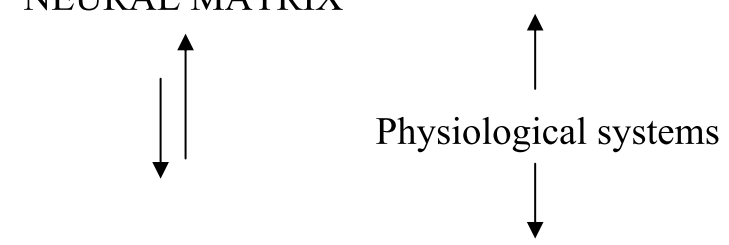

VISCERAL MATRIX

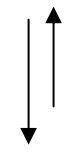

INPUT (to/from the VISCERA)

Figure 1. Sensory Input from the External Environment

The nature, structure and conformation of our genes influences the nature and level of the proteins which are expressed however it is our phenotype (influences such as $\mathrm{pH}$ and temperature) which influence protein conformation, the levels of minerals and cofactors, and the rate at which expressed proteins react.

An adequate level of exposure to light is essential to maintain the levels of calcitriol (vitamin D3), bilirubin, nitric oxide and many other neural and visceral processes. Light of specific 
wavelengths activates many of the physiologically significant proteins ${ }^{9}$. The action of light stimulating the production of Vitamin D3 influences the function of up to 3,000 of the estimated 10-25,000 genes which encode for proteins and the production of an estimated 200 antimicrobial peptides.

Light comprises an estimated $85 \%$ of sensory input and hence is the predominant way in which we experience and perceive our environment. It is therefore the dominant way in which we experience the positive and negative (stress) influences. For instance if we see a car crash but cannot hear, smell or touch the event it becomes somewhat surreal. It takes the combined effect of vision and hearing to transmit the significance of the event and of the urgency to act e.g. to extract car passengers from further danger and injury. For instance a person who does not have hearing may be oblivious of impending danger even if they see the danger unfolding e.g. someone running towards them - with what purpose?

Light or vision requires other sensory inputs (hearing, smell, taste or touch) in order to give significance ${ }^{10}$ (see Figure 1). Multi-sensory input is an essential component of the body's complex multi-level function ${ }^{11}$ i.e. mono-sensory input on its own cannot convey the significance of an event. The spectrum of light absorbed and emitted by proteins influences cognition, in particular colour perception and visual contrast $(b / w)$ i.e. of the magno- and parvo-cellular pathways. This is often seen in developmental dyslexia in which the speed and coordination of sensory processing is altered by prevailing biological deficits ${ }^{12}$.

The frequency of sensory input (at EEG frequencies) influences system function i.e. networks of organs and cells ${ }^{13}$. Visceral input influences the reaction conditions (temperature, $\mathrm{pH}$, levels of minerals and vitamins), protein conformation, cell morphology and the rate at which proteins react. Altered protein conformation, $\mathrm{pH}$, levels of minerals and cofactors influences the spatial distribution of proteins in the cell and ultimately alters cell morphology and the function of different physiological systems. The orthodox or prevailing understanding of physiological systems ${ }^{13}$.

\section{Physiological systems}

Brain function to manage unregulated physiological activity. It does so through a mechanism involving the autonomic nervous system which includes an understanding of the significance, nature and structure of the physiological systems.

Historical definition: Cardiovascular, Respiratory, Nervous, Skin, Musculoskeletal, Blood, Digestive, Endocrine, Urinary, Male \& Female Reproductive

Amended Definition: Breathing, Blood pressure, Blood Glucose, Blood Volume, Blood Cell Content, Digestion, Elimination, Sexual, pH, Temperature, Osmotic pressure, Posture, Sleeping, Communication

This revised understanding of the significance of the physiological systems incorporating acid/base regulation, temperature, and sleep allows a greater understanding of how many 
CAM techniques can be of value i.e. treating the causes of dysfunction; and allows us to look critically at the role of pharmaceuticals i.e. which treat the biochemical consequences of systemic dysfunction.

\section{Therapeutic sub-types}

Pharmaceuticals are essential components of modern medicine. They block the developing pathological processes which are ultimately manifest as symptoms. They block the production and/or absorption of key metabolites which influence brain function but they do not prevent the onward manifestation of the stress-related processes. There is a distinct difference between cause and symptom. If not, how can nutrients (antioxidants, vitamins, minerals, cofactors, etc) obtained from diet ${ }^{18}$ protect against disease or vice versa i.e. the lack of nutrients contribute to the onset of disease(s) ${ }^{19}$ ?

In addition most pharmaceuticals are mono-biological yet the processes of dysfunction may have many causes and have a multi-systemic nature $14,15,16$. This is recognised in combination drug products e.g. involving a heart drug and diuretic. This revised understanding or definition of the physiological systems and sensory input leads us to an improved understanding of the role played by many CAM techniques ${ }^{17}$.

i. Systems-based Biofeedback

Breathing Buteyko, Meditation ${ }^{\mathrm{TM}}$, Exercise (swimming, walking, running), Ayurvedha

Digestion: Nutrition/Diet, Ayurvedha

Elimination: Colonic Irrigation

Posture: Alexander Technique, Chiropathy, Osteopathy, Kinesiology, Massage techniques, Pilates, Yoga.

Temperature: $\quad$ Sauna, Turkish baths

and Sleep

ii. Frequency-based Biofeedback

Biofeedback, Hemi-Sync, Neurofeedback; Psychological interventions, Cognitive Behavioural Therapy (CBT); Hypnosis.

iii. Sensory-based Biofeedback

Light $^{20,21}$ : Colour/Light Therapy, Syntonic Optometry, Coloured lenses, Light-based biofeedback systems, Ayurvedha

Sound: Sound-based Biofeedback systems, Sound-based relaxation techniques, Music

Touch: Massage techniques

Smell: $\quad$ Aromatherapy

Taste:

Vocal: $\quad$ Biosonics

iv. CAM Techniques which Lack an Apparent Scientific Rationale 


\subsection{Acupuncture}

As acupuncture can replace the use of anaesthetics e.g. in open-heart surgery, there can be little doubt that it adapts a most significant medical concept. It appears likely to be a pseudopharmacological intervention which links the EEG theta frequencies and the production of pain masking mu-opioids/cannabinoids ${ }^{22}$. The idea that Acupuncture can be explained by a network of energy channels or Qi which run beneath the skin's surface appears to contradict orthodox biomedical research findings. If someone undergoes surgery would this interrupt the flow of Qi? Nevertheless this flow of energy, or Qi, is influenced by hereditary factors, stress, trauma, grief, infection and nutrition. This indicates a link with the autonomic nervous system. Furthermore, that acupuncture points are distributed around the body, and also that stimulating these biologically active points (singly or in combination) can relieve pain, links the function of acupuncture to that of the physiological systems (e.g. breathing, blood pressure and digestion), autonomic nervous system, and to cellular and molecular biology. In addition, the acupuncture points can be stimulated by different modalities e.g. light, sound (Sonopuncture) and micro-currents (Voll electroacupuncture ${ }^{23}$, Rydoraku)

Changes to cell morphology are linked to the EEG or resonant frequencies e.g. delta frequencies are linked to physical damage and the processes of repair whilst theta frequencies are, arguably, associated with pain management and advanced thought processes. They are the clear evidence of the body's multi-level function. In essence, the lower the frequency the greater the indication of physical damage and the need for neuropeptides or mu-opioids. For example it takes up to 30 seconds for pain to develop following a significant trauma (e.g. car accident, bullet wound, etc). This is indicative of the speed of transmission by the central nervous system but also of the rapid response by pain-modulating cannabinoids. Changes of cellular morphology have biochemical, structural, resonant and electrochemical properties, each in a dynamic relationship with the others. Changes to one parameter will influence the stability of the others. In addition the acupuncture points have lower electrical resistance than the surrounding skin. This may be evidence of altered local structures e.g. accumulation of neuropeptides at acupuncture points ${ }^{24}$.

\subsection{Homeopathy}

Arguably this is a pharmacological intervention ${ }^{25}$. We cite the example of Materia Medica Holding, a major research-based Russian pharmaceutical company which, for more than 10 years, has developed and manufactured a new class of medicines based upon a homeopathic technology i.e. which are based upon the use of ultra low doses of (polyclonal) antibodies. Such is the significance of their work, that major and minor pharmaceutical companies have established research groups to investigate this potentially fruitful area of research.

\section{Proof of concept}

It is completely disingenuous to dispute the efficacy of CAM techniques especially so when such modalities are used throughout the world with clear therapeutic effect. Moreover that 
such techniques have inherent side-effects indicates that such techniques can have a positive or negative effect e.g. side-effects, contraindications or risks are associated with flashinglight therapies, acupuncture, homeopathy, colonic irrigation, osteopathy etc. There is a significant scientific principle involved e.g.

- Flashing lights can cause photosensitivity but can also be used with therapeutic effect e.g. flashing lights can invoke photosensitive migraine and epilepsy but can also be adapted with therapeutic effect (Biofeedback) to treat migraine.

- $\quad$ Reported side-effects with acupuncture include accidental injury to visceral organs and nerves, bleeding, muscle spasms, bruising, fainting ${ }^{26}$.

- There are several published reports of patients experiencing extremely dangerous side effects as a result of colon hydrotherapy. These side effects include potentially fatal electrolyte imbalances and perforations of the colon during the insertion of the colonic tube.

- The potential of side-effects when combining different CAM techniques which have differing modes of action.

That many get relief from using CAM techniques indicates the value of such techniques ${ }^{27}$ and of the limitations of orthodox biomedicine (which largely ignores the influence of phenotype).. Often patients use CAM techniques when orthodox biomedicine fails to provide relief or the expected level of medical recovery. CAM techniques are based upon reestablishing balance and of lowering the overstimulation of the autonomic (or visceral) sympathetic nervous system and/or perhaps of raising the understimulation of the parasympathetic nervous system. This is increasingly linked to the function of the medulla and vagus nerve - polyvagal theory ${ }^{28,29}$. This is a different physiological context by comparison with pharmaceuticals. It addresses the fundamental cause whereas drugs treat only the symptoms of dysfunction.

\section{Virtual scanning}

Light is fundamental to the body's physiological stability ${ }^{6,9}$. It is the medium which delivers circa $85 \%$ of our sensory input. The benefit of a summer vacation in the sun to recharge our metaphorical batteries has long been accepted. Different light frequencies can stimulate different physiological processes e.g. the production of calcitriol (Vitamin D), bilirubin, nitric oxide ${ }^{30}$, etc.

Virtual Scanning is a cognitive technique which has diagnostic and therapeutic significance. It is based upon the light absorbing and emitting properties of proteins. Accordingly (i) by measuring the spectrum of light emitted it is possible to determine the levels of proteins expressed and the rate at which such expressed proteins react in each pathological process (see Appendix 1, example report; and Appendix 3, case studies), (ii) to identify the location and state of development of developing pathologies and changes to cell morphology (see Appendix 2), and (iii) provide a mono-chromatic light-based biofeedback therapy ${ }^{31,13}$ which can activate inactivated processes and proteins and hence contribute to improved homeostasis and lessened morbidity (see Appendix 4). Such technique holds the prospect of being a better and more cost-effective option than genetic screening. 
Virtual Scanning arose out of research into the medical application of industrial lasers. From these origins a research team led by I.G.Grakov established a biological response to a waveform i.e. that the body responded to monochromatic light. This led to the development of a mathematical model which linked cognitive input, in particular the visual perception of colours, to the autonomic nervous system. Ultimately this model (and associated algorithms) was developed to include an understanding of the nature and significance of the physiological systems - an area of great significance to medicine - because a doctors' consultation is based upon a rudimentary assessment of physiological stability i.e. of systemic stability. This has been overlooked by researchers as they seek to adapt a systemsbiology approach (i.e. of bottom-up systems biology) to better understand the vagaries of molecular biology.

It is widely recognised that the visceral organs are organized in systems however the prevailing or orthodox explanation (see section 3) has inhibited further research in this area. How is it possible to research such phenomena? What tools are available to conduct the validating research? Moreover, if the visceral organs are organized in systems/structures, as is widely accepted, how are these structures regulated? Systems may not be able to be biochemically regulated. This is a major dilemma for orthodox biomedicine which, in recent years, has focussed upon genetic research to the apparent exclusion of almost every other aspect of biomedical research. For example in their efforts to cultivate cells using artificial animal embryos and uterus, leading embryologist Dr Hung-Ching Liu and coworkers found that cells began to divide and went to full term but all produced significantly deformed embryos. What is not yet known is the process which the brain/body uses to regulate cell growth.

The evidence that twins (identical and otherwise) can have completely different health outcomes illustrates that phenotype is far more significant than genotype i.e. that our sensory experiences and nutritional habits can be manifest as stress and ultimately as greater levels of morbidity and premature mortality. The stresses to which we are exposed can overcome our genetic characteristics.

Each and every medical condition must have a genetic component and an environmental component (phenotype) i.e. (i) of proteins expressed, (ii) of the rate at which expressed proteins subsequently react with their reactive substrates, and (iii) include the reaction conditions ( $\mathrm{pH}$, temperature, levels of substrates, etc) which influence the rate at which expressed proteins react with their reactive substrates. These reaction conditions (physiological systems) influence the rate of every physiologically significant reaction and extraction. They are part of the neuro-regulatory system which manages all aspects of the body's function.

\section{Discussion}

This understanding of how CAM techniques function forms the basis for a mathematical model of the consequences of cognition, in particular of visual perception, which has been linked to the function of the physiological systems ${ }^{32-34}$ and the autonomic nervous system ${ }^{5,6}$. 
It includes a first mathematical model of the physiological systems. This has been incorporated into a medical technique 'Virtual Scanning' 35-37 which has diagnostic and therapeutic significance, and which uses cognitive input as the data sets for this particular mathematical model. As outlined it may provide a theoretical framework or explanation for most CAM techniques. Furthermore this leads us to consider the biological manifestation of the laws of physics in which the flow of current i.e. of biophotons, through the body's electromagnetic field(s) has a physiological effect.

- Different metallic acupuncture needles have a different effect/polarity ${ }^{38}$. This is especially significant in bimetallic acupuncture needles.

- The insertion of acupuncture needle stimulates nerve fibres which send a stimulus to nerve fibres in the spinal cord and mid brain. This releases endophins which have the effect of modulating what we perceive to be pain.

- In addition the acupuncture effect stimulates the release of beta-endorphin and ACTH from the pituitary gland. ACTH stimulates the release of cortisol from the adrenal glands i.e. the acupuncture effect is an anti-inflammatory effect acting upon inflammatory processes at the cellular level.

- Altered flow of biophotons i.e. of electrical current.

i. Greater levels of natural sunlight act to re-establish homeostasis whilst lowered levels of natural sunlight act to restabilise homeostasis.

ii. Different colours influence the energetic characteristics of the electrical current.

iii. The light emitted by proteins as they react provides a flow of biophotons with different energetic characteristics

iv. Different pulsed/EEG frequency of the electrical current will influence the physiological effect

v. The characteristics of biophotons/light emitted will alter depending upon the characteristics of the medium in which the light is being transmitted

- Altered physiology causes variation to the prevailing electromagnetic field ${ }^{39}$ and can have a local or systemic effect.

Acupuncture Needle

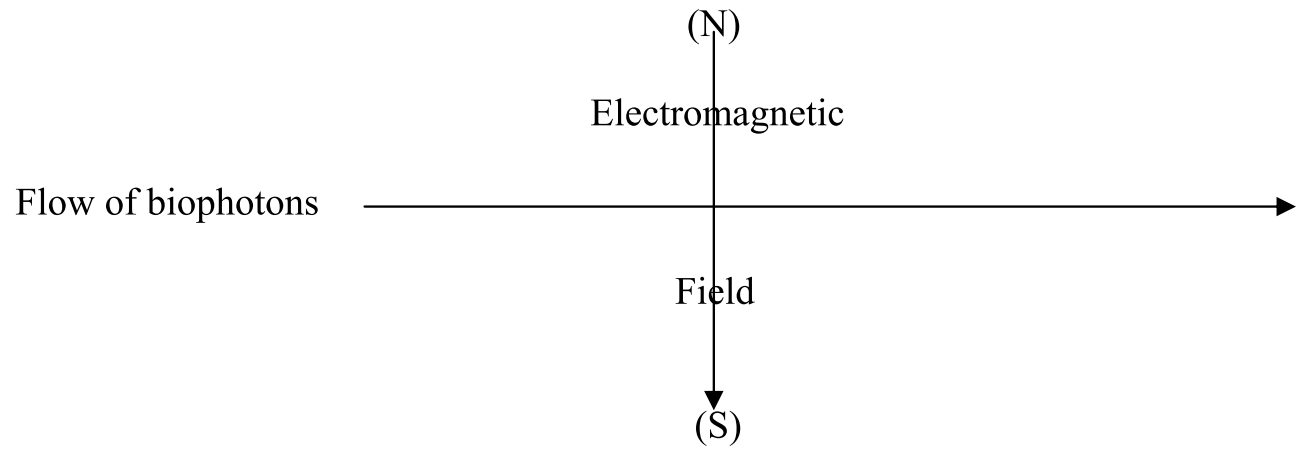

Figure 2. Diagram 
There is a biodynamic relationship between an electric current (the flow of energy/biophotons through the meridians), the local electromagnetic field (a factor of the local physiology/ pathology), and the polarity of the needle. In an electric motor an electric current in a magnetic field will experience a force however in the body this dynamic cannot be similarly expressed. In the body changes to the electric current or flow of biophotons, and the polarity of the needle (by selecting needles of different metals or thickness), will influence the local electromagnetic field and hence must influence local physiology, in particular that of the autonomic nervous system and physiological systems i.e. it can influence coordination and function but not the basic structures. The meridians are components in a sophisticated electrical transmission system which has outlets along this sophisticated electrical circuitry i.e. the acupoints are electromagnetic focal points or plugs which have a strong electromagnetic effect. This effect changes when pathologies develop within organs and organ systems.

\subsection{Physiological principles}

As outlined, most CAM techniques function at different levels of physiological significance. They are applied independently of other CAM modalities - a criticism which is usually leveled at orthodox biomedicine! Nevertheless at which level of physiological significance can the CAM modality be expected to function? The use of acupuncture e.g. in open-heart surgery, clearly illustrates the significance of such technique. Despite this there is not yet an accepted understanding of how acupuncture works. In India Ayurvedha is widely used. The complexity of such approaches are such that it can only be applied by the most experienced, well trained and intelligent practitioners.

\subsection{Clinical applications}

A good diagnosis is essential for any trained practitioner irrespective of their specialism. Orthodox medicine lacks an inexpensive screening modality therefore they only find what they are looking for. Doctors are fallible. Genetic screening is now being introduced yet such technique identifies the genes associated with a medical condition yet this makes the erroneous assumption that specific genes or gene groups of gene associations can be markers for specific diseases. It is known that in type 2 diabetes the genetic associations differ between racial sub-types. It is also known that altered lifestyle e.g. of improved diet, exercise and better lifestyles, alters the genetic profile i.e. that phenotype is a more significant factor than genotype. The theoretical basis upon which pharmaceutical medications is based is gene-based and hence is limited. Every person is different and will respond differently to any form of medication. Areas of potential clinical application and benefit for phenotype-based approaches include:

- The use of an appropriate CAM therapy to complement the use of a drug, as in neurooncology.

- to stimulate the lymphatic system in order to better eliminate neurotoxins produced by chemotherapy or radiotherapy 
- to re-establish the balance of the digestive and eliminatory systems i.e. without drugs

- to suppress overstimulation of the autonomic nervous system e.g. in asthma, hay fever, etc.

- to work alongside nutritional deficits in cases of mineral supplementation.

- to prevent the onset or progression of stress-related conditions

- to re-establish synchronized neural activity e.g. in Parkinsonism/as an option to deep brain stimulation ${ }^{40}$.

- $\quad$ to re-establish the stability of the nervous structures ${ }^{41,42}$.

\subsection{Summary}

It is inconceivable that the human body is not a neurally regulated system. Moreover the nature of this regulated system can only be explained by what has hitherto been researched in the name of the medical sciences and this must include feedforward by the brain to the organs and feedback by the organs to the brain. There must also be a recognition of the link between sensory input and its ultimate expression as changes to cellular and molecular biology. For there to be a regulated system there has to be an understanding of what exactly is the role of the brain i.e. 'to regulate the body's function and unregulated physical activity, process cognitive input, fix and access memories, and the process which we recognise as thought/compute/plan/calculate'.

Secondly, it is not possible to have a comprehensive approach to the management of health unless you address both the fundamental stress-related origins AND the symptoms of disease.

Thirdly, the extent or level of the ailment leads to changes to cell morphology and ultimately to the onset of pathologies. Throughout all forms of medicine the same theme arises i.e. of balance, of the sympathetic and parasympathetic nervous system, of 'hyper'function and 'hypo'function, fight or flight, nature and nurture, the brain and the body, of yin and yang. What we recognise as pathologies is due to 'autonomic dysfunction' and ultimately to autonomic failure i.e. 'degeneration'.

Such a wholistic concept illustrates the theoretical superiority of an integrative approach to medicine. The question is no longer whether CAM techniques work but instead (i) to what extent do they work and (ii) how viable are such techniques in the hands of trained practitioners? Practitioners cannot just apply a frequency or flashing light without an appreciation that such techniques have the potential, not just to treat autonomic dysfunction, but also to induce dysfunction and side-effects. All forms of medicine must be applied by the most experienced, well trained and intelligent practitioners.

Computer-based techniques have been introduced in all walks of life to improve the quality of products and services offered. They are used in manufacturing and in surgical procedures to eliminate the variability due to human involvement i.e. 'doctors are human and humans make mistakes'. Virtual Scanning may be such a technology. 


\section{Appendix}

Example report

\begin{tabular}{|l|l|}
\hline Last Name & \\
\hline Name & \\
\hline Sex & Woman \\
\hline Age & 59 years. \\
\hline Weight & $77,000 \mathrm{~kg}$. \\
\hline Additional information & Migraine \\
\hline Diagnostics date & 31 August 2004 (15:03:45) \\
\hline
\end{tabular}

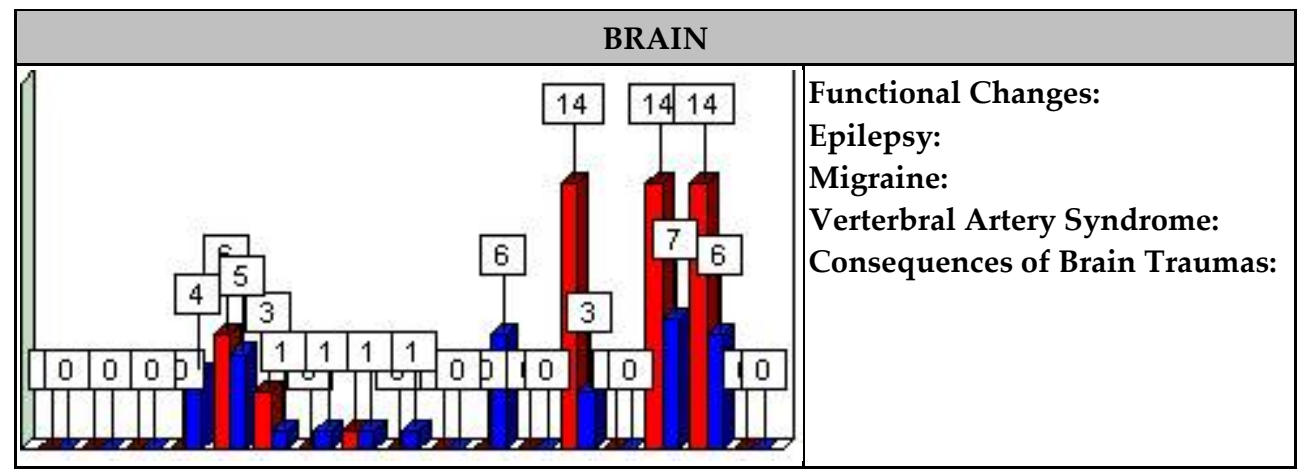

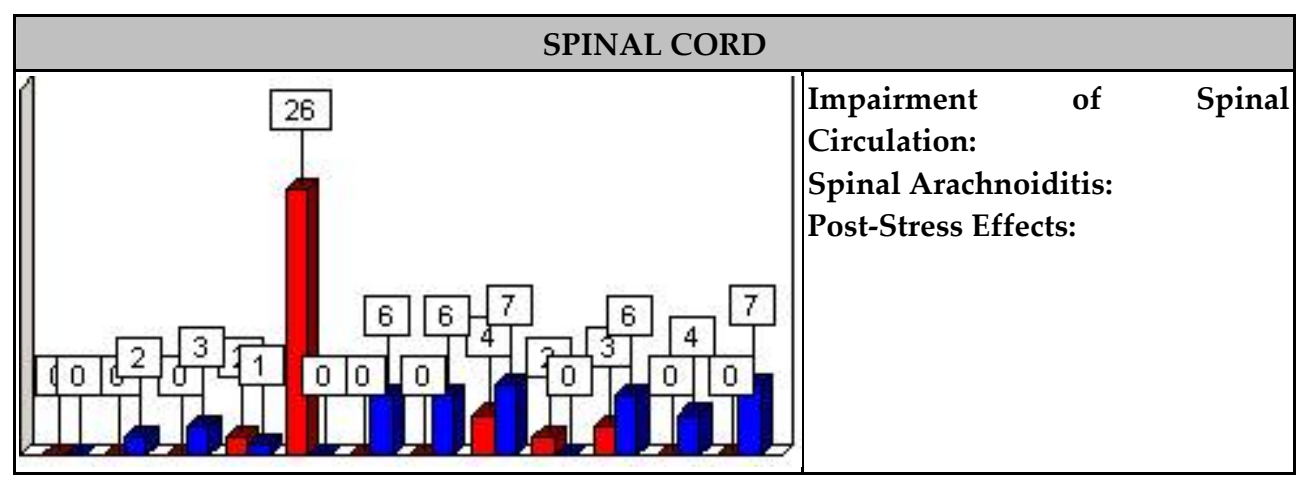



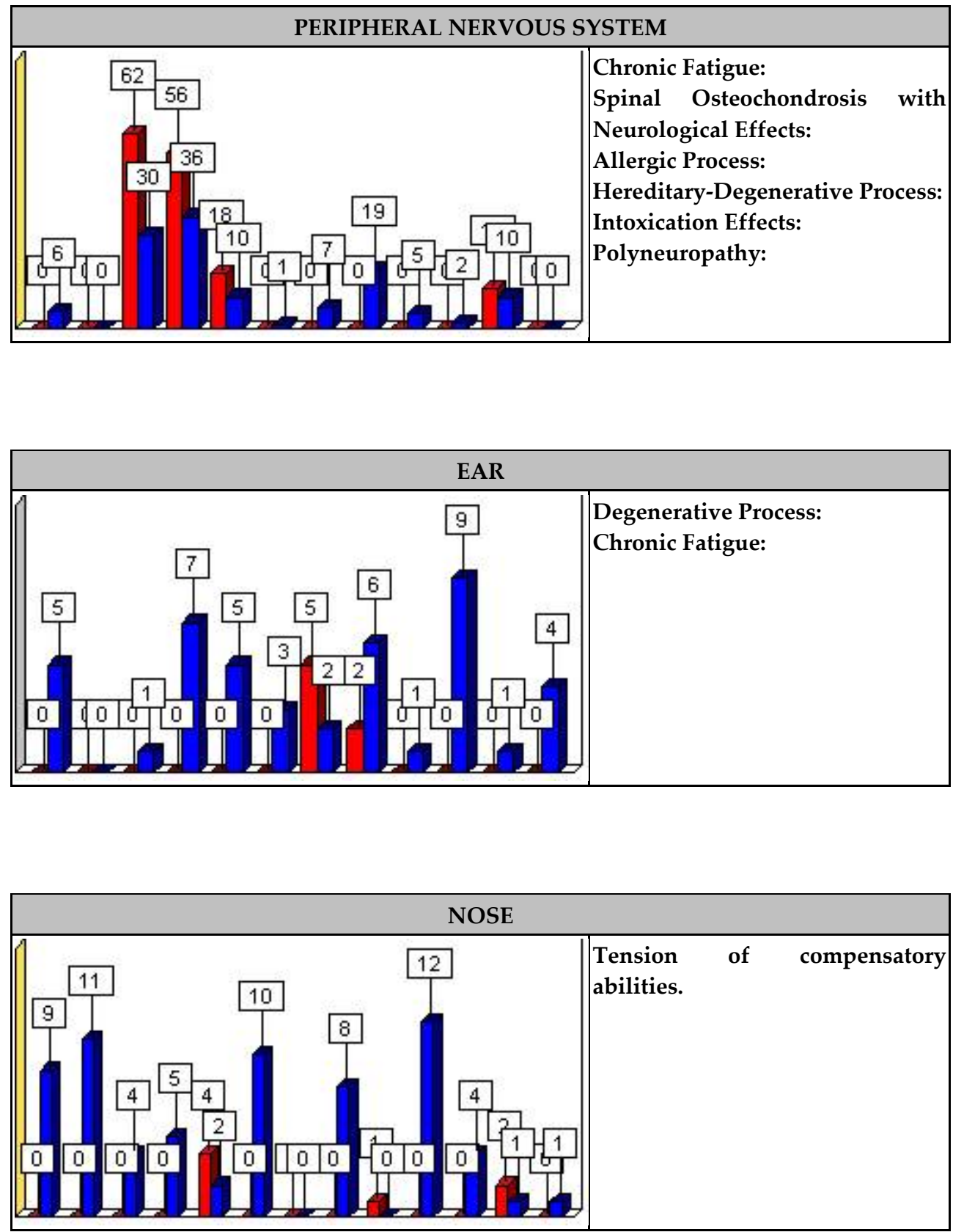

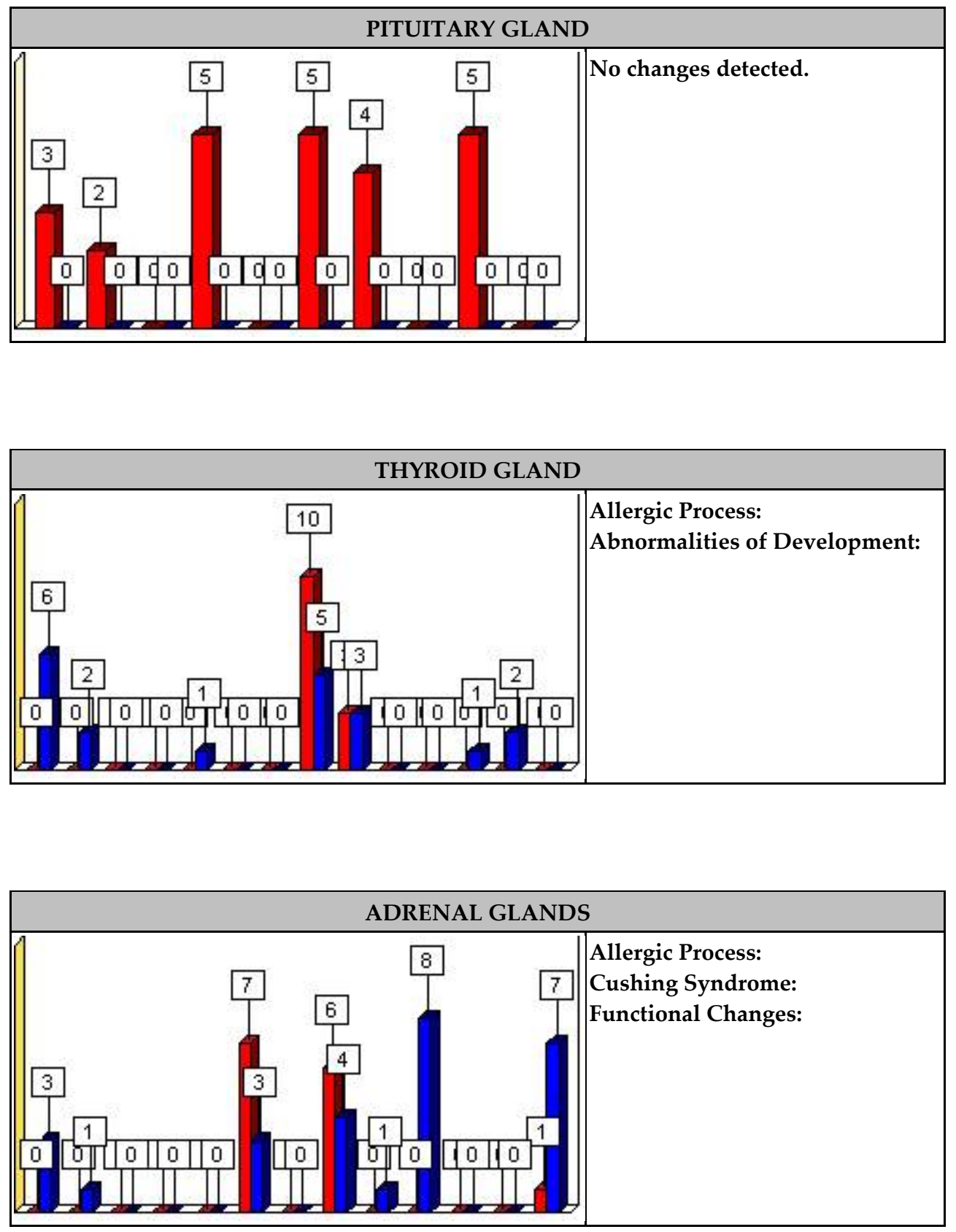

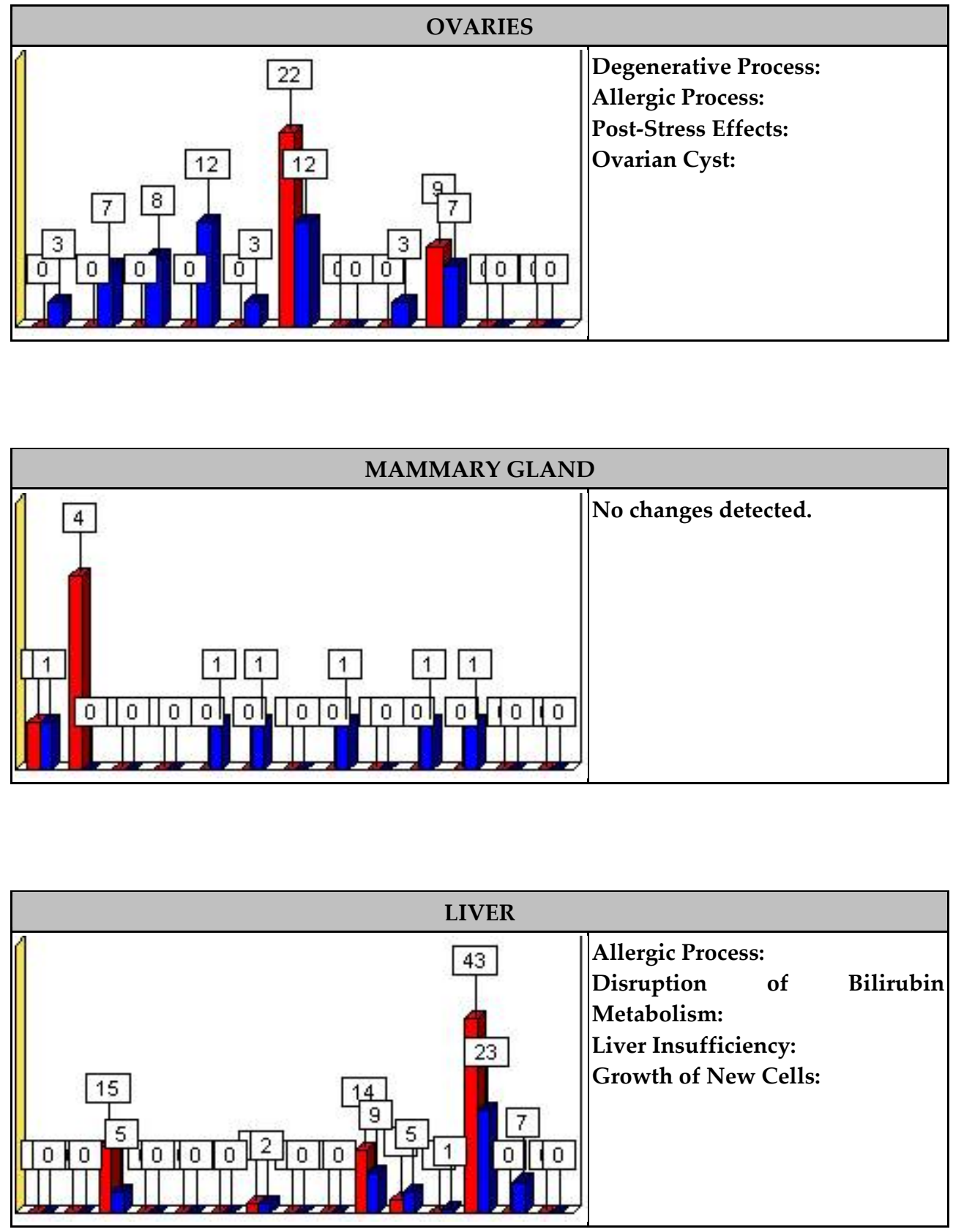

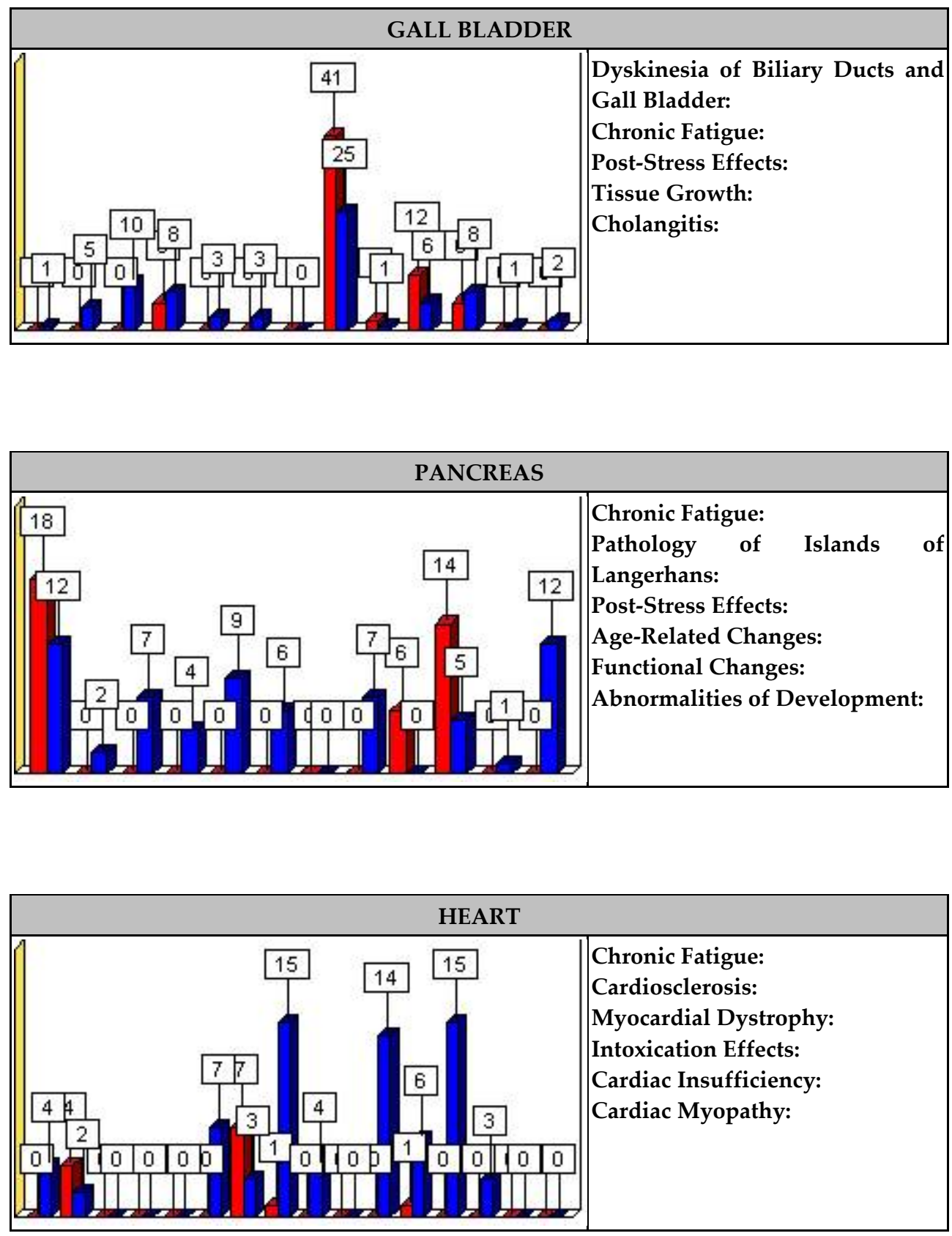

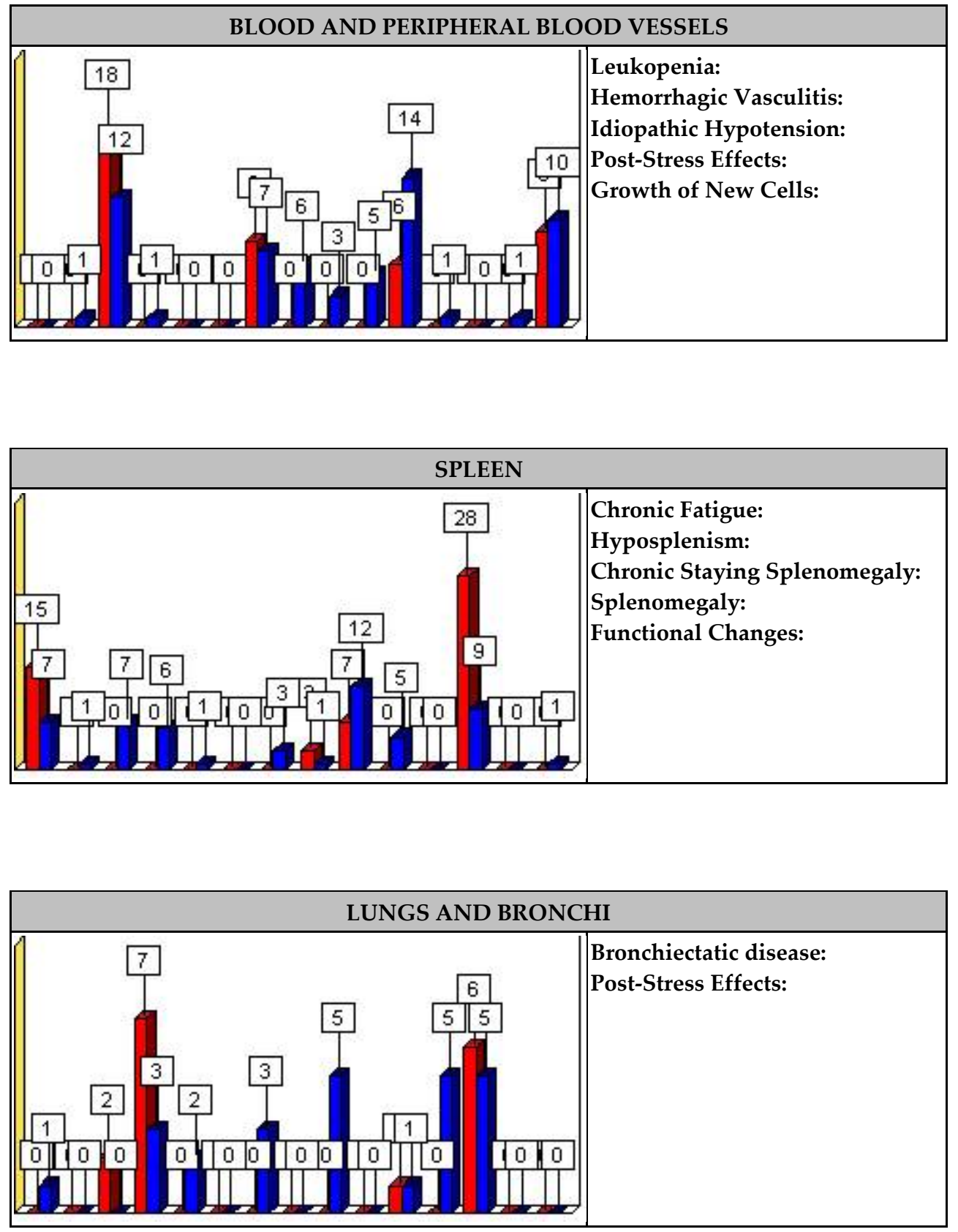

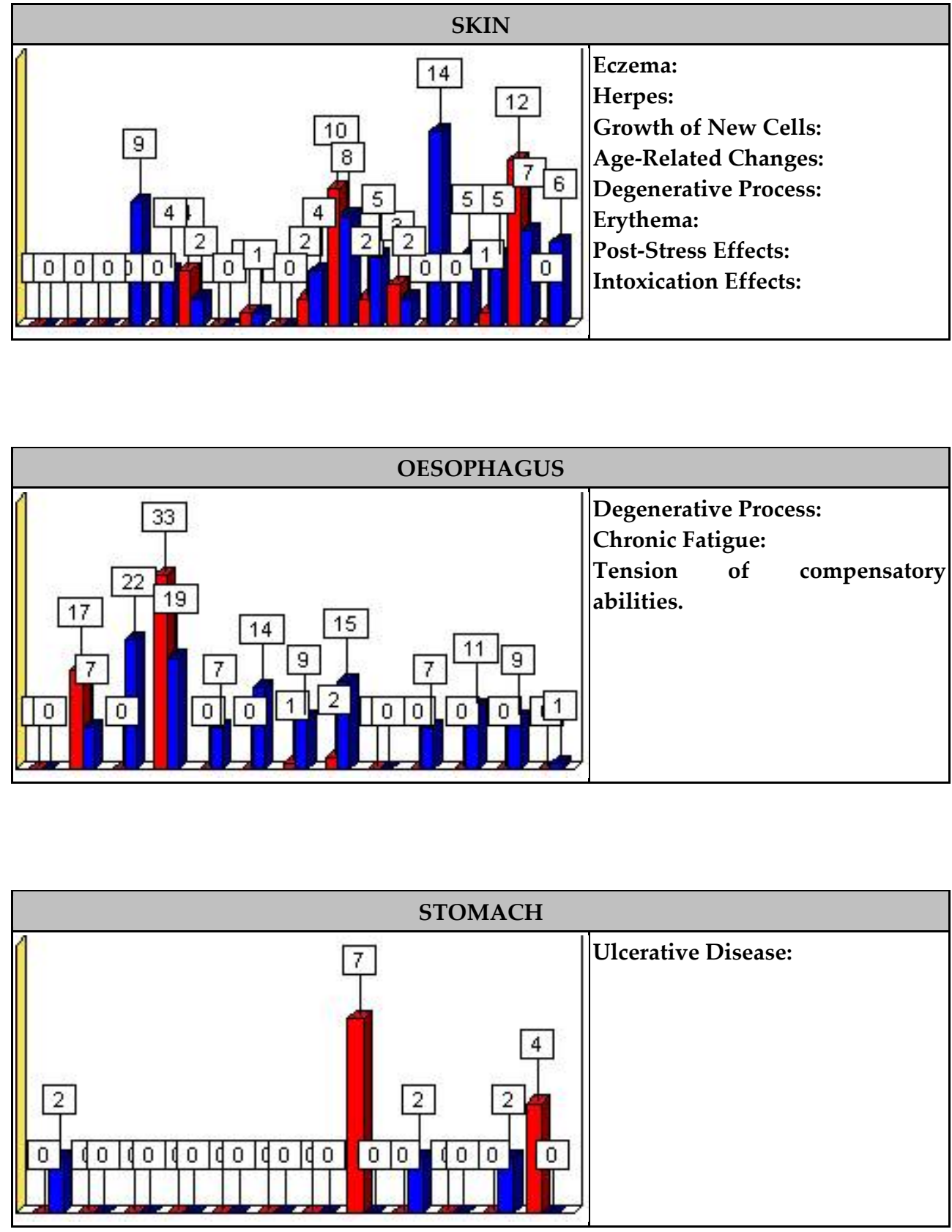

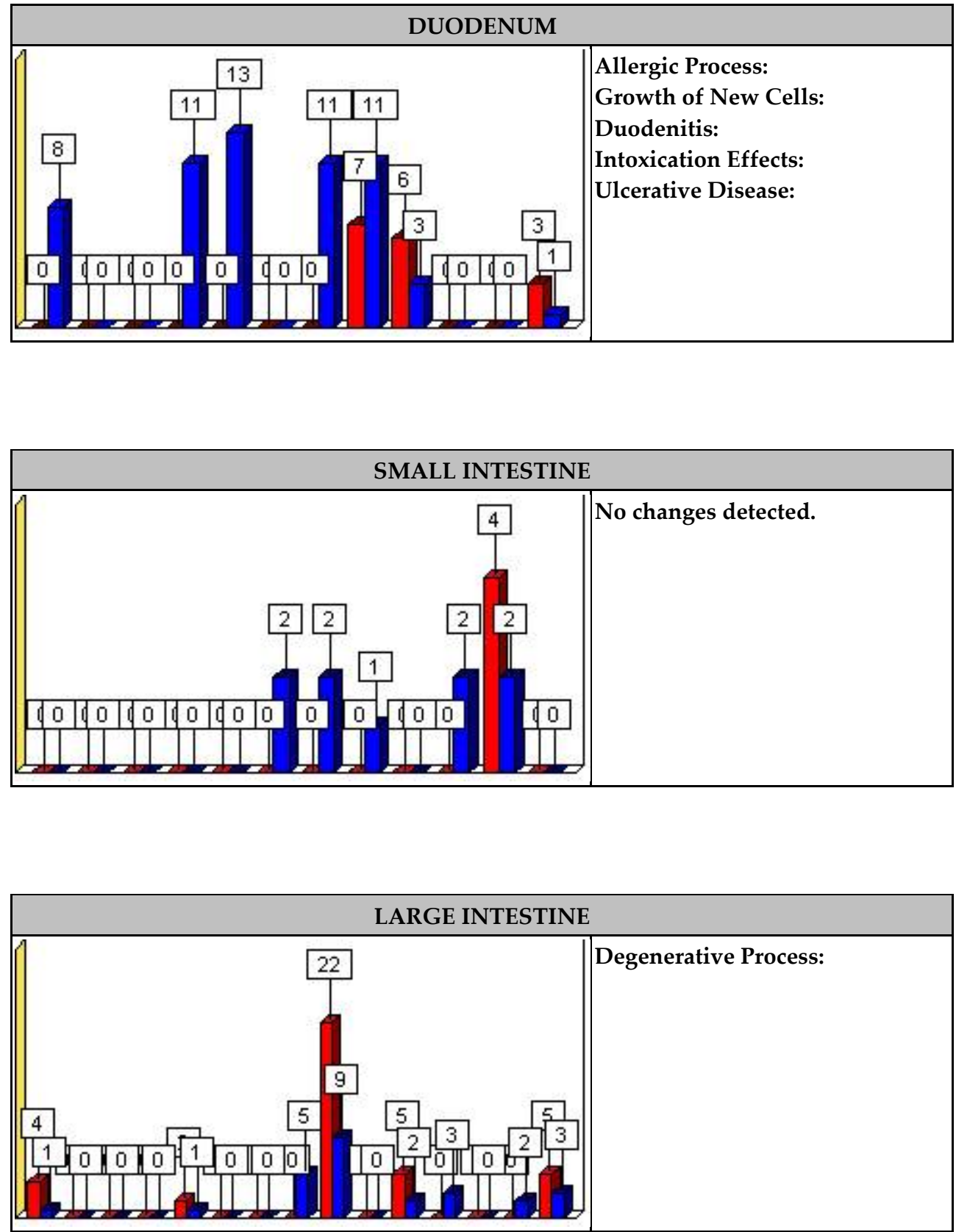

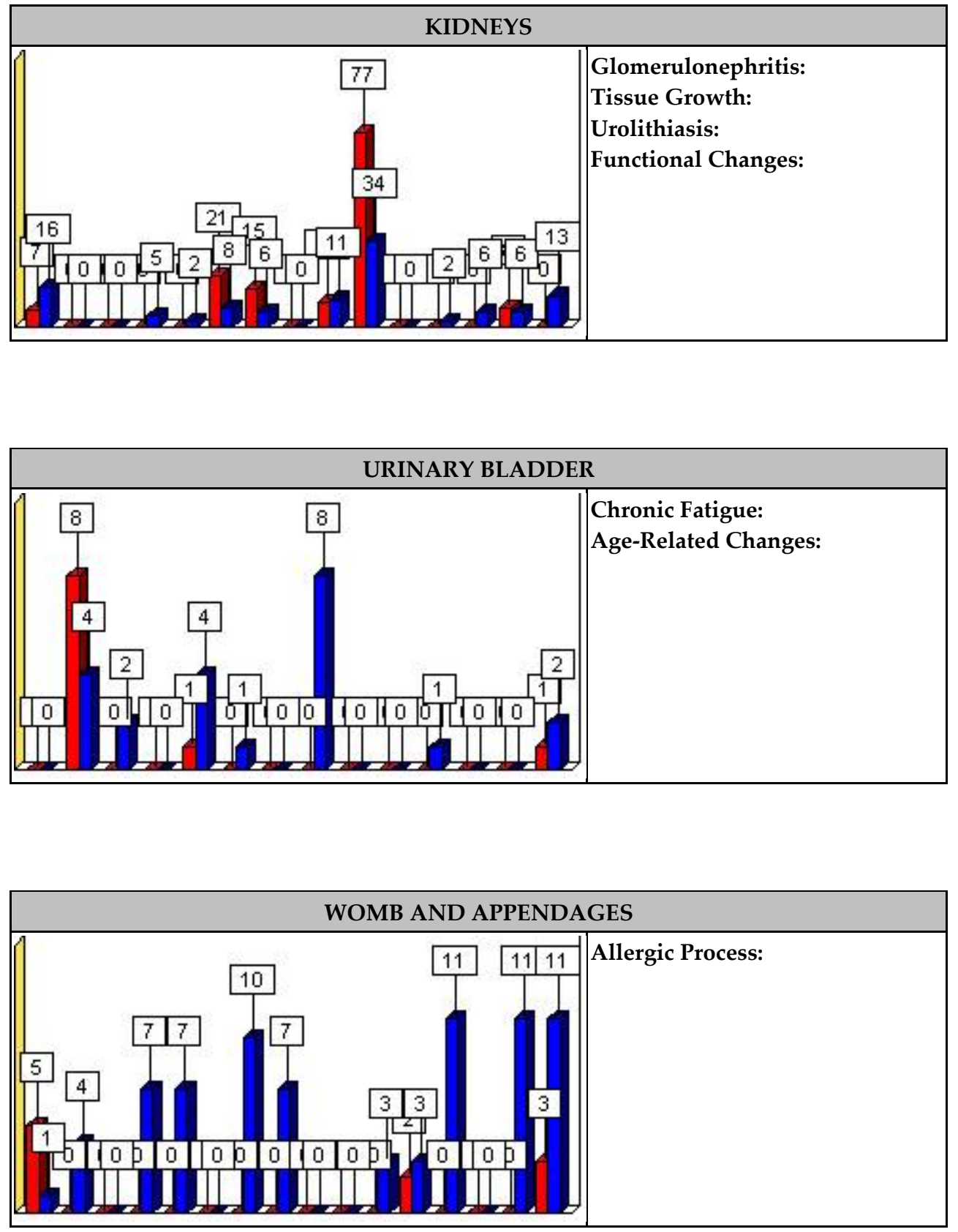


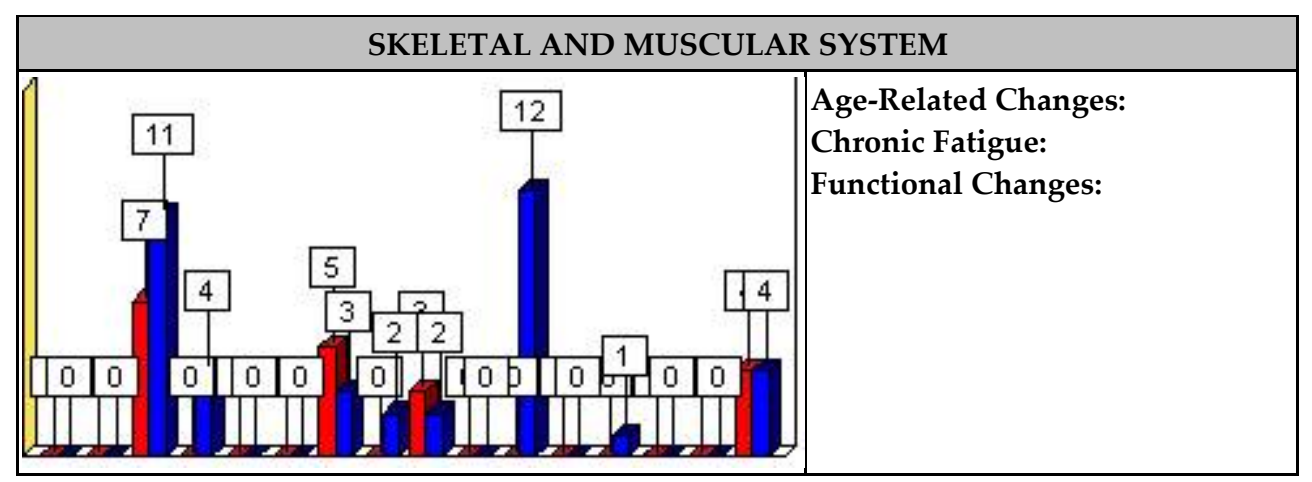

\section{Images of cell morphology}

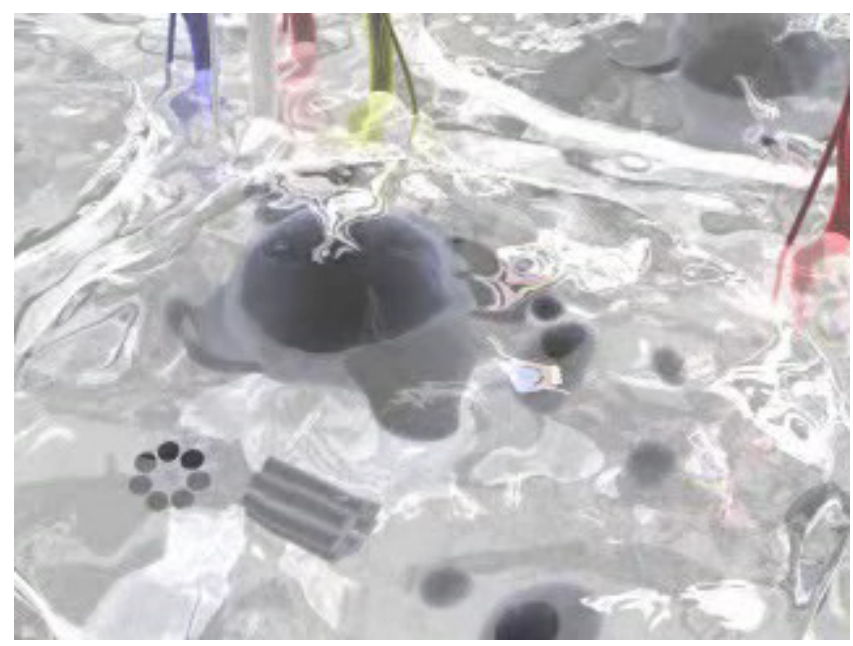

Normal cellular processes 


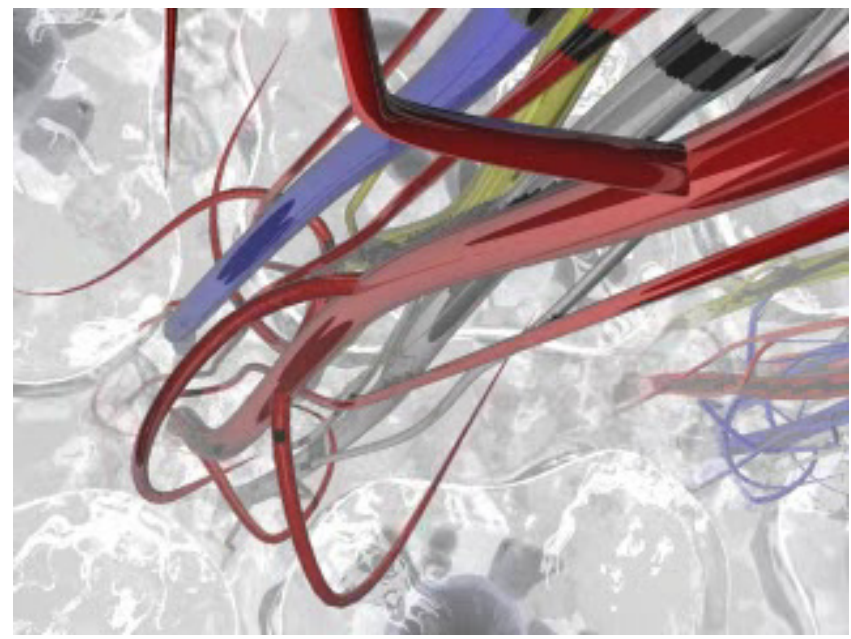

Inc blood flow/ Inflammation

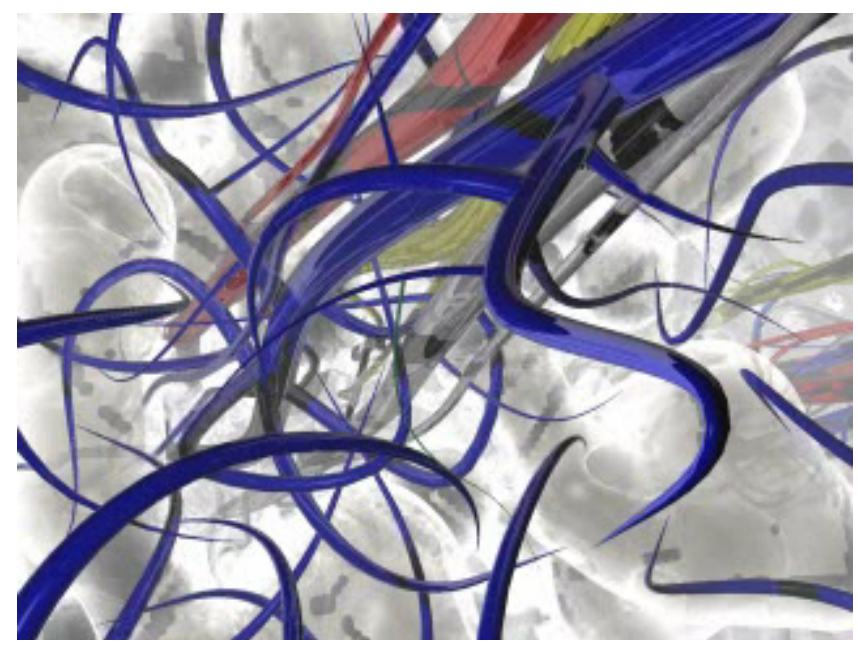

Ischaemia 
Does the Cognitive Top-Down Systems Biology Approach, Embodied in Virtual Scanning, Provide Us with a Theoretical Framework to Explain the Function of Most Complementary and Alternative ... 105

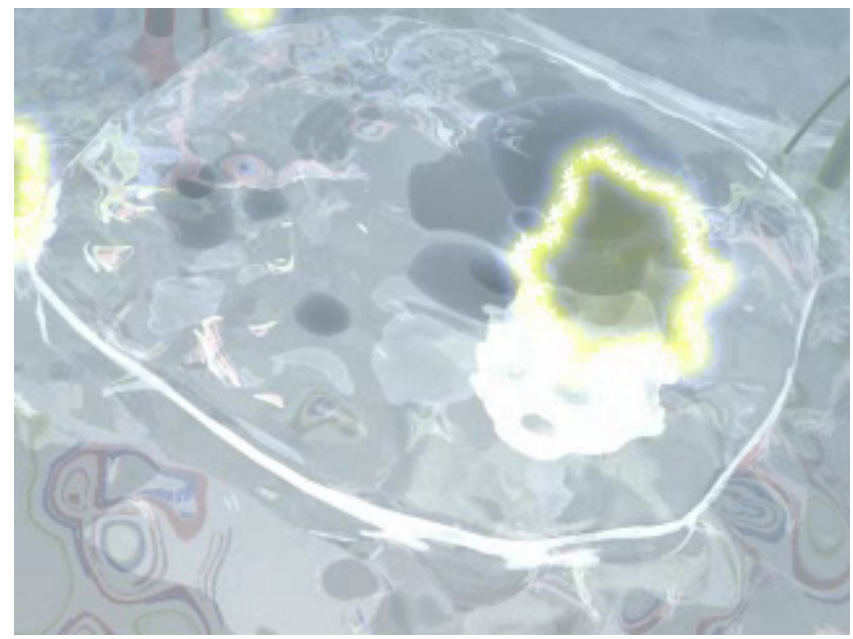

Cell hypofunction

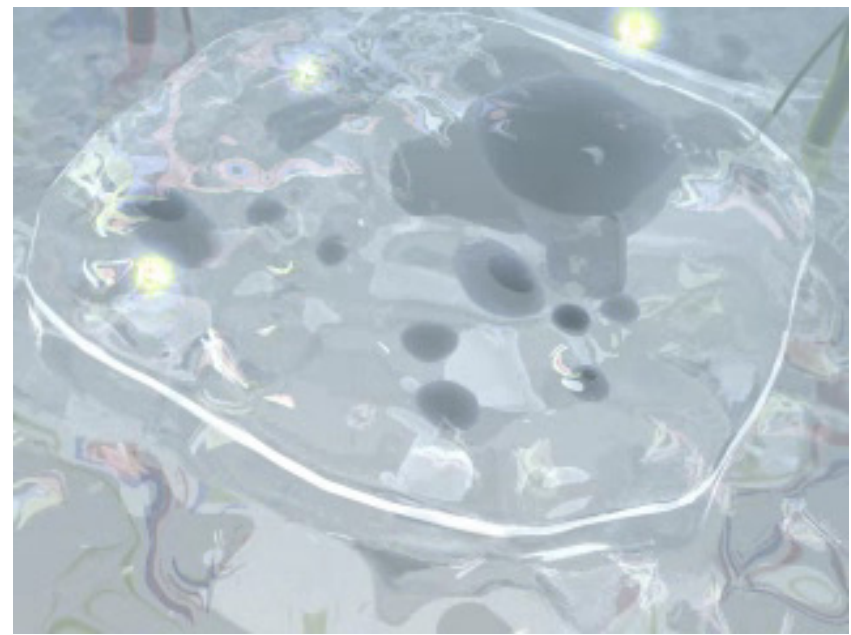

Cell hyperfunction 


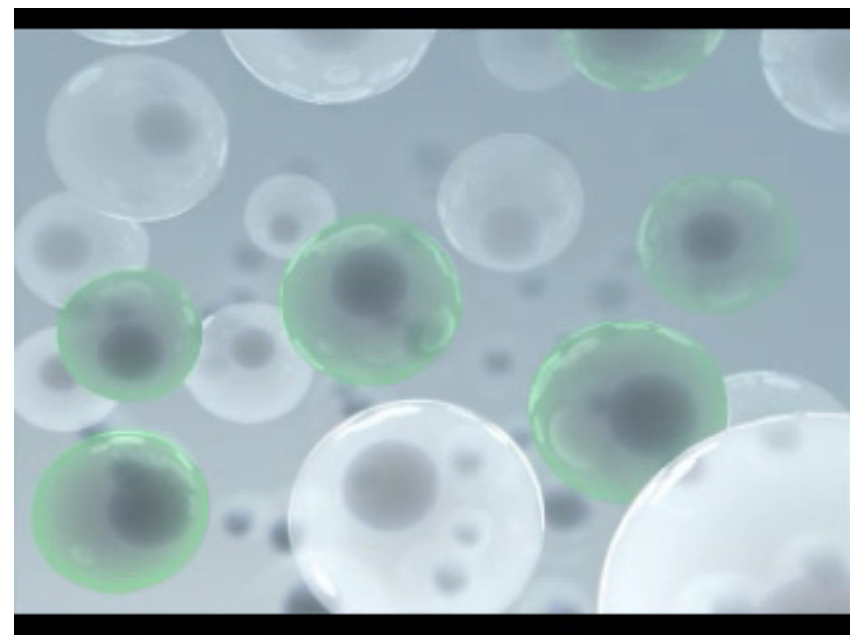

Abnormality of a limit of cell division

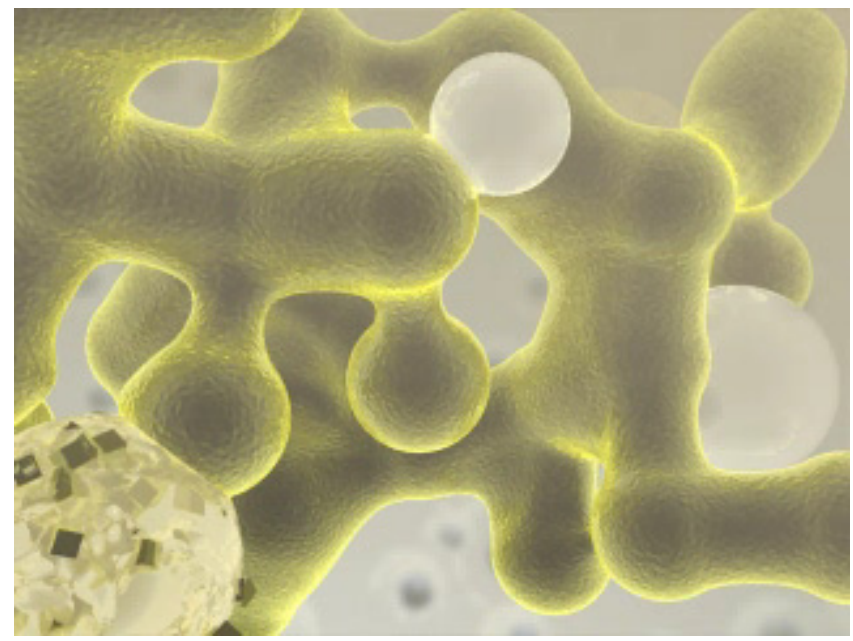

Old cells

\section{Examples of diagnostic effect}

1. female, 50 yrs. A VS practitioner with history of lymphoblastic leukaemia. VS identified the reoccurrence of the condition although medical tests had shown a steady level of leukocytes. As she had previously been treated for leukaemia and her most recent test had shown a steady level of leukocytes she discounted the possibility of reoccurrence of her lymphoblastic leukaemia. A subsequent medical check identified the reoccurrence of leukaemia. 
2. female, c45 yrs. A lady with fatigue had been receiving acupuncture for several years. Medical testing was not able to identify the problems. VS indicated a number of issues including the early onset of pancreatic cancer. The lady died of pancreatic cancer several years later.

3. female, 50 yrs with duodenal problem. GP advised that she did not have a problem. Virtual Scanning detected process of duodenal ulcer. GP under duress carried out a further consultation and again gave a negative report. She was admitted to hospital with blood discharges just one week later and spent over one week in hospital being treated for a perforated duodenal ulcer. The lady gained a compensatory settlement as a result of the misdiagnosis by the GP.

4. the Medical Director of a reputable hospital in England asked Montague Healthcare to illustrate the scope of Virtual Scanning to diagnose the health of a patient. Within 15 minutes of completing the test Montague Healthcare had advised a list of five medical conditions. The results were confirmed by the Medical Director. He commented that his hospital did not have the ability to provide such diagnosis.

\section{Examples of therapeutic effect}

1. female, 59 years, who experienced migraines from the age of 11 until 59 years. Increasingly severe migraine attacks - the most recent resulted in her being Admitted to hospital in a semi-conscious state.

The VS health assessment showed indications of migraine, epilepsy, impaired cerebral circulation, impaired spinal circulation as a result of vertebral artery syndrome, osteochondrosis and idiopathic hypotension. Since starting VS therapy she has not had any further migraine symptoms and is now completely free of migraines. In addition, several years previously she had a single mastectomy to remove cancer. This involved removal of the lymph nodes which resulted in poor drainage and hence swelling of her arm. After 4 months Virtual Scanning therapy there was little, if any, remaining swelling in her arm.

2. male, 78 years was dissatisfied with his GP's diagnosis when he consulted him with type 2 diabetes, circulatory problems and a swollen foot. He became disillusioned with the diagnosis when prescribed antibiotics. After a 6 month course of VS colour therapy he has improved stability of blood sugar levels, improved mobility, improved circulation, improved energy, and dramatically improved quality of life.

3. male, c65yrs suffering from dysarthria who could only mumble gutturally for almost 5 years. His hospital could not identify the problem despite using MRI, checking for Parkinsonism and Alzheimers, and finally was unable to assist him. Virtual Scanner detected encephalopathy, impairment of cerebral circulation, etc. VS colour therapy enabled him to recover the ability to speak clearly within 6 days.

4. dyslexic female, 11yrs. The first indications of improved writing (distinct) and reading were indicated by the third VS consultation. Her end of term report commented that her reading ability had been re-assessed as that of a 14yo. Following a change of school this child completed her first examinations. Of the 11 examinations 9 were passed at 
grades $1 \& 2$ (greater than $70 \%$ ) whilst the remaining two examinations were grade 3 $(60-70 \%)$.

5. male, 76 years with prostate and asbestos-induced lung cancer. Poor prognosis, required assistance to walk. Following chemotherapy and radiotherapy he had severely restricted breathing due to fluid on the lungs which required surgical intervention to drain fluid from his lungs but which failed to cure the problem of accumulating fluid. After a course of VS colour therapy, medical scanning techniques (x-rays) showed the complete absence of fluid on his lungs. As a result he no longer had chronic breathing insufficiency, he could walk unaided and his overall health was much improved. He lived for 1-2 years more than medical expectations.

\section{Author details}

Graham Wilfred Ewing

Montague Healthcare, Nottingham, United Kingdom

\section{References}

[1] Spear BB, Heath-Chiozzi M, Huff J. Clinical Applications of Pharmacogenetics. Trends in Molecular Medicine 2001; 7(5):201-204

[2] Ewing GW, Grakov IG. Fashion or Science? How can orthodox biomedicine explain the body's function and regulation? N.Am.J.Med.Sci. 2012;4(2):57-61.

[3] Malarkey WB, Kiecolt-Glaser JK, Pearl D, Glaser R. Hostile behaviour during marital stress alters pituitary and adrenal hormones. Psychosomatic medicine 1994;56(1):41-51.

[4] Grippo AJ, Lamb DG, Carter CS, Porges SW. Social isolation disrupts autonomic regulation of the heart and influences negative affective behaviors. Biological Psychiatry 2007;62:1162-1170.

[5] Ewing GW, Ewing EN. NeuroRegulation of the Physiological Systems by the Autonomic Nervous System - their relationship to Insulin Resistance and Metabolic Syndrome. J. Biogenic Amines 2008;22(4-5):208-239.

[6] Ewing GW, Ewing EN. Cognition, the Autonomic Nervous System and the Physiological Systems. J. Biogenic Amines 2008;22(3):140-163.

[7] Sudakov KV. The basic principles of the general theory of functional systems. Medicine 1987;S.26-49.

[8] Kryzhanovskii GN, Adrianov OS, Bekhtereva NP, Negovskii VA, Sudakov KV, Khananashvili MM. Integrative activity of the nervous system in health and in disease. Vestnik Rossiǔskoŭ akademii meditsinskikh nauk 02/1995.

[9] Ewing GW, Parvez SH, Grakov IG. Further Observations on Visual Perception: the influence of pathologies upon the absorption of light and emission of bioluminescence. The Open Systems Biology Journal 2011;4:1-7.

[10] Chifferstein HNJ, Talke KSS, Oudshoorn D-J. Can Ambient Scent Enhance the Nightlife Experience? Chemosensory Perception 2011;4(1-2):55-64. 
[11] De Araujo IE, Simon SA. The gustatory cortex and multisensory integration. International Journal of Obesity 2009;33(Suppl. 2): S34-43.

[12] Ewing GW, Parvez SH. The influence of Pathologies and EEG frequencies upon sense perception and coordination in Developmental Dyslexia. A Unified Theory of Developmental Dyslexia. N.Am.J.Med.Sci. 2012;4(3):109-116.

[13] Ewing GW. A Theoretical Framework for Photosensitivity: Evidence of Systemic Regulation. Journal of Computer Science and System Biology 2009;2(6):287-297.

[14] Ewing GW, Parvez SH. The Dynamic Relationship between Cognition, the Physiological Systems, and Cellular and Molecular Biochemistry: a Systems-based Perspective on the Processes of Pathology. Act. Nerv. Super. Rediviva 2010; 52(1):29-36.

[15] Ewing GW. There is a need for an Alternative or Modified Medical Paradigm involving an understanding of the nature and significance of the Physiological Systems. N.Am.J.Med.Sci. 2010;2(6):1-6.

[16] Ewing GW, Parvez SH. The Multi-systemic Nature of Diabetes Mellitus: genotype or phenotype? N.Am.J.Med.Sci 2010;2(10):444-456.

[17] Ewing GW. Does an improved understanding of the nature and structure of the Physiological Systems lead to a better understanding of the therapeutic scope of Complementary \& Conventional Medicine? Journal of Computer Science and Systems Biology 2009;2(3):174-179.

[18] Bowman GL, Silbert LS, Howieson D, Dodge HH, Traber MG, Frei B, Kaye JA, Shannon J, Quinn JF. Nutrient Biomarker Patterns, Cognitive Function and MRI Measures of Brain Aging. Neurology 2012;78:1-1.

[19] Ewing GW. The Regulation of $\mathrm{pH}$ is a Physiological System. Increased Acidity alters Protein Conformation and Cell Morphology and is a Significant Factor in the onset of Diabetes and other common pathologies. The Open Systems Biology 2012;5:1-12.

[20] Ewing GW, Parvez SH, Grakov IG. Further Observations on Visual Perception: the influence of pathologies upon the absorption of light and emission of bioluminescence. The Open Systems Biology Journal 2011;4:1-7.

[21] Horwitz LR, Burke TJ, Carnegie DH. Augmentation of Wound Healing Using Monochromatic Infrared Energy. Advances in Wound Care 1999;12:35-40.

[22] Melzack R, Wall PD. Pain mechanisms: a new theory. Science 1965;150(3699): 971-9.

[23] Voll R. Twenty years of electroacupuncture in Germany: a progress report. Am.J. Acupunct 1975;3:7-17.

[24] Ji-Sheng Han. Acupuncture: neuropeptide release produced by electrical stimulation of different frequencies. Trends in Neurosciences 2003;26(1):17-22.

[25] http://www.materiamedica.ru/en/

[26] Ernst E. Deaths after acupuncture: A systematic review. The International Journal of Risk and Safety in Medicine 2010;22(3):131-6.

[27] Vasquez A. "Allopathic Usurpation of Natural Medicine: The Blind Leading the Sighted." [Editorial] Naturopathy Digest 2006, February.

[28] Porges SW. The Polyvagal Perspective. Biological Psychology 2007;74:116-143.

[29] Porges SW. The Polyvagal Theory: phylogenetic contributions to social behavior. Physiology and Behavior 2003;79:503-513. 
[30] Belvisi MG, Stretton CD, Yacoub M, Barnes PJ. Nitric oxide is the endogenous neurotransmitter of bronchodilator nerves in humans. European Journal of Pharmacology 1992;210(2):221-2.

[31] Vysochin Yu et al, 2001. Methodology and Technology of Invigoration of Different Population Orders. In: Consolidated 5 year Research Plan of Physical Training, Sports and Tourism State Committee of the Russian Federation. 2000. English translation available at: http://www.montaguehealthcare.co.uk/files/Vysochin/Vysochin.pdf

[32] Ewing GW, Parvez SH. The Multi-systemic Nature of Diabetes Mellitus: genotype or phenotype? N.Am.J.Med.Sci 2010;2(10):444-456.

[33] Ewing GW. Mathematical Modeling the Neuroregulation of Blood Pressure using a Cognitive Top-down Approach. N.Am.J.Med.Sci.2010;2(8):341-352.

[34] Ewing GW, Parvez SH. Mathematical Modeling the Systemic Regulation of Blood Glucose: 'a top-down' Systems Biology Approach. NeuroEndocrine Letters 2011;32(4):3719.

[35] Grakov IG. Strannik Diagnostic and Treatment System: a Virtual Scanner for the Health Service. Minutes of Meeting No. 11 of the Praesidium of the Siberian of the Academy of Medical Sciences of the USSR (AMN) held in Novosibirsk 4 December 1985.

[36] Hankey A, Ewing EN. New Light on Chromotherapy: Grakov's 'Virtual Scanning' System of Medical Assessment and Treatment. eCAM 2007;4(2):139-144.

[37] Ewing GW, Ewing EN, Hankey A. Virtual Scanning - Medical Assessment and Treatment. Journal of Alternative and Complementary Medicine 2007;13(2):271-286.

[38] Gaponiuk Pia, Perov IuF. Electrode potentials of acupuncture needles made of different metals [Article in Russian]. Vopr. Kurortol. Fizioter. Lech. Fiz. Kult. 1981 Jan-Feb;(1):46-9.

[39] Eachou Chen. De-chi and propagated sensation along meridian. Journal of Accord Integrative Medicine 2011;7(3):116-118.

[40] Kringelbach ML, Jenkinson N, Owen SLF, Aziz TA. Translational principles of deep brain stimulation. Nature Reviews Neuroscience 2007;8:623-635.

[41] Salansky N, Fedotchev A, Bondar A. Responses of the Nervous System to Low Frequency Stimulation and EEG Rhythms: Clinical Implications. Neuroscience and Biobehavioural Reviews 1998;22(3):395-409.

[42] Bell G, Marino A, Chesson A, Struve F. Electrical states in the rabbit brain can be altered by light and electromagnetic fields. Brain Research 1992;570(1-2):307-315. 